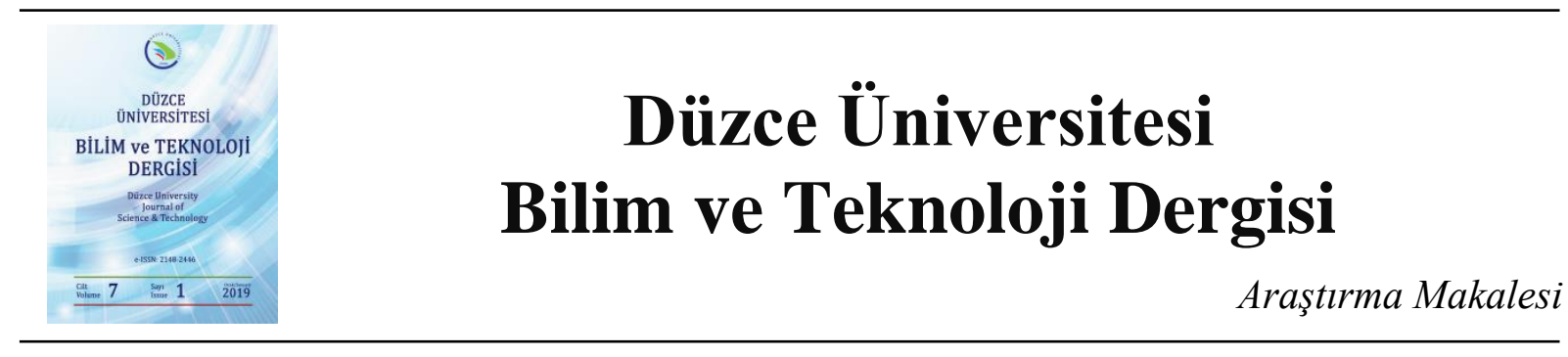

\title{
WLAN/WiMAX Uygulamaları için Geniş Bant Mikroşerit Dipol Anten Tasarımı
}

\author{
Adnan SONDAŞ ${ }^{a}{ }^{*}$ \\ ${ }^{a}$ Bilişim Sistemleri Mühendisliği Bölümü, Teknoloji Fakültesi, Kocaeli Üniversitesi, Kocaeli, TÜRKİYE \\ * Sorumlu yazarın e-posta adresi: asondas@kocaeli.edu.tr
}

\begin{abstract}
ÖZET
Mikroşerit antenler az hacim kaplamaları, hafif ve yüzeye uyumlu olmaları, fazla maliyet gerektirmemeleri, üretimlerinin kolay olması gibi avantajları nedeni ile günümüzde kablosuz haberleşmenin birçok alanında sıklıkla tercih edilmektedirler. Bu yapıların en büyük dezavantajları ise dar bantlı performans sergilemeleridir. Çalışmalarda bu sorunu gidermek için anten geometrisi ile oynanarak veya antene yeni eklemeler yapılarak daha geniş bantlı karakteristikler elde edilmiştir. Literatürdeki geniş bantlı mikroşerit tasarımlar incelendiğinde, klasik mikroşerit dipol antenlerin bu uygulamalar için pek tercih edilmedikleri görülmektedir.

Bildiride, WLAN/WiMAX uygulamalarında kullanılabilecek olan geniş bantlı klasik bir mikroşerit dipol anten tasarımı tanıtılmaktadır. Tasarımda, dipol elemanın beslemesi yakınlarına asimetrik ve aynı düzlemde olacak şekilde bükülmüş şerit yüklemeler eklenmiştir. Bu dipol ve yükleme elemanlarının rezonansları birbirine yaklaştırılarak da geniş bantlı anten performansı elde edilmiştir. İlgili tasarım \%43'lük frekans bant genişliğine sahiptir ve $2.36-3.67 \mathrm{GHz}$ aralı̆̆ında performans göstermektedir. Tasarım ilgili bantta yönsüz bir ışıma örüntüsüne ve $2.36 \mathrm{dBi}$ seviyelerinde yönlendirme kazancına sahiptir. Bildiride, önerilen anten tasarımının CST Microwave Studio benzetim programı ile elde edilmiş sayısal analiz sonuçlarına yer verilmektedir. Ayrıca tasarımın geometrik boyutlarının anten performansına olan etkilerini anlayabilmek için bazı parametrik çalışmalar da yapılmış ve bildiride bu parametrik analiz sonuçlarına da yer verilmiş̧ir.
\end{abstract}

Anahtar Kelimeler: WLAN/WiMAX; Mikroşerit dipol anten; Geniş bant anten

\section{A Wideband Microstrip Dipole Antenna Design for WLAN/WiMAX Applications}

\begin{abstract}
These days, microstrip antennas are preferred in many areas of wireless communication, due to their advantages such as low volume coverage, light weight, surface compatibility, high cost requirements and easy production etc. Also microstrip antennas have these advantages as well as disadvantages such as low gain, low power operation and narrow bandwidth etc. The main disadvantages of these antennas are their narrow band performance $(\sim 10)$.
\end{abstract}


In this study, a classical wideband microstrip dipole antenna design which can be used in WLAN/WiMAX applications (covering the bands $2.4-2.5 \mathrm{GHz}$ and $2.5-3.5 \mathrm{GHz}$ ) is introduced. Proposed antenna design has a frequency bandwidth of $43 \%$ and performs at $2.36-3.67 \mathrm{GHz}$. Note that $\left|\mathrm{S}_{11}\right| \leq-10 \mathrm{~dB}$ criterion with $50 \Omega$ system impedance is considered. Antenna design has a non-directional radiation pattern with a gain of $2.36 \mathrm{dBi}$ and with a total efficiency of $-0.428 \mathrm{~dB}$. In this report, numerical analyses results of the design are obtained by using CST Microwave Studio. Also a number of parametric studies have been carried out to show the parameters which affect the performance of the proposed antenna design.

Keywords: WLAN/WiMAX; Microstrip dipole antenna; Wideband antenna

\section{GiRiș}

$\mathrm{M}$ ikroşerit antenler, az hacim kaplamaları, hafif ve yüzeye uyumlu olmaları, fazla maliyet gerektirmemeleri, üretimlerinin kolay olması gibi birçok avantaja sahip olduklarından dolayı kablosuz haberleşme sistemlerinde sıklıkla kullanılmaktadırlar. Bu antenler, minyatür boyutları sayesinde küçük boyutlu cihazların dışına ya da içine kolayca yerleştirilebilir, yüzeye uyumlu olmalarından dolayı da uçak, füze ve uydu gibi özel hassasiyet gerektiren araçların aerodinamik yapısını bozmadan bu araçların üzerine monte edilebilmektedirler. Gerektiğinde devre elemanları ile aynı taban malzemesi üzerine yerleştirilmesi sonucunda elde edilen tümleşik anten sistemiyle daha ideal bir elektriksel performans sağlanabilmektedir. Ayrıca bu antenlerden çoklu-bant karakteristiği elde edilebilirken, tasarım üzerinde yapılan küçük oynamalar sayesinde doğrusal veya dairesel kutuplanmış 1şıma karakteristiği de elde edilebilmektedir [1].

Mikroşerit antenlerin bu avantajların yanı sıra, düşük kazanç, düşük güçte çalışma ve dar bant genişliği gibi dezavantajlara da sahiptir [2, 3]. Bu dezavantajların başında ise bant genişliklerinin dar olması $(\sim$ \%10) gelmektedir. Literatürde yapılan bazı çalışmalar sonucunda Defense Advanced Research Project Agency (DARPA)'ya göre \%25, Federal Communication Commission (FCC)'ye göre \%20 olarak kabul edilen geniş bant sınırı [4] mikroşerit antenler için de aşılmaya başlanmıştır.

Literatürdeki geniş bantlı mikroşerit tasarımlar incelendiğinde, klasik mikroşerit dipol antenlerin bu uygulamalar için pek tercih edilmedikleri görülmektedir. Olan çalışmalar incelendiğinde ise dipol elemanlara farklı yüklemelerin eklenmesi [5-7] kıvrımlı yapıların kullanılması [8,9] gibi yöntemler ile geniş bantlı anten performansının elde edilebileceği gözlemlenmiştir.

Bu çalışmada, [7]'de klasik bir dipol antenin bant genişliğini artırmak için uygulanmış yöntemlere (maksimum \%22'lik performans elde edilmiştir) alternatif olan ve daha geniş bant performansına sahip olan mikroşerit dipol anten tasarımı tanıtılmıştır. İlgili anten, geniş bant uzun mesafe internet erişimi (Worldwide Interoperability for Microwave Access-WiMAX, 2.4-2.5 GHz) ve kablosuz yerel ağ (Wireless Local Area Network-WLAN, 2.5-3.6 GHz) uygulamalarında kullanılmak üzere tasarlanmıştır. 


\section{MikroșERIT Dipol ANTEN TASARIMI}

Önerilen mikroşerit anten konfigürasyonu ve ilgili tasarım parametreleri Şekil 1'de verilmektedir. Görüldüğü üzere, bu tasarımda $52 \mathrm{~mm}(\sim \lambda / 2)$ uzunluğundaki mikroşerit dipol antene, iki adet bükülmüş yükleme elemanı, besleme konumuna asimetrik ve aynı düzlemde olacak şekilde eklenmiştir. İlgili anten yapısı CST Microwave Studio programında modellenirken, metalik yapılar için $0.05 \mathrm{~mm}$ kalınlığındaki kayıplı bakır plakalar $(\sigma=5.8 \times 107 \mathrm{~S} / \mathrm{m})$ kullanılmıştır. Bu plakalar $60 \times 22 \mathrm{~mm}^{2}$ boyutlarındaki ve $0.79 \mathrm{~mm}$ yüksekliğindeki kayıplı Arlon DiClad $880\left(\varepsilon_{r}=2.2\right)$ dielektrik malzemesi üzerine yerleştirilmiştir. Ayrıca, anten 1şımasının daha geniş açılarda ve yönsüz olabilmesi için de anten yapısında toprak düzlemi kullanılmamıştır.

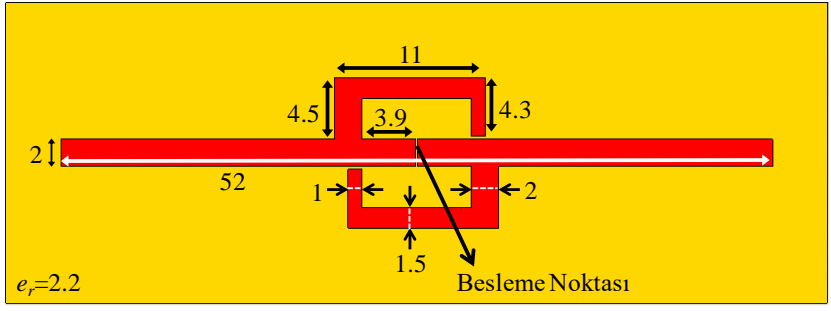

Şekil 1. Önerilen anten tasarımı (boyutlar mm)

Önerilen anten tasarımında yükleme elemanları varken (Yüklemeli) ve yokken (Yüklemesiz) sergilediği geri-dönüş kaybı $\left(S_{11}\right)$ karakteristiği ve giriş empedans karakteristiği sırası ile Şekil 2 ve Şekil 3'te verilmiştir. Görüldüğü üzere, dipol elemanı tek başına iken $2.29-2.56 \mathrm{GHz}$ aralığında \%11'lik bant genişliği performansı göstermektedir. Önerilen tasarımda, dipol elemanına bükülmüş yüklemeler eklenerek ve boyutları ayarlanarak, bu elemanların sahip oldukları iki farklı frekans bandı bir araya getirilmiştir. Böylece ilgili tasarımdan 2.36-3.67 GHz frekans aralığında \%43'lük geniş bantlı bir anten performansı elde edilmiştir.

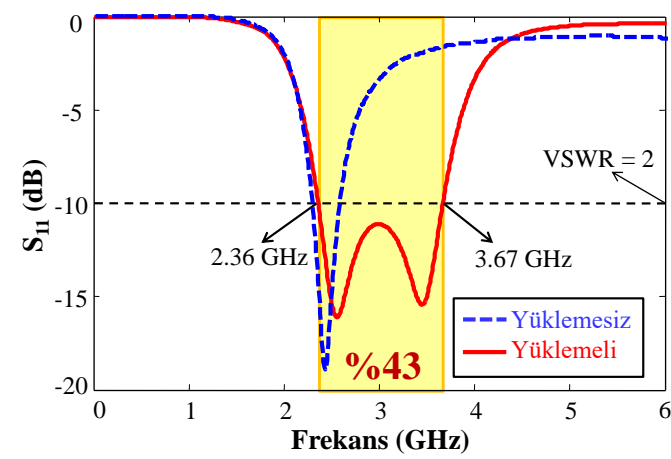

Şekil 2. Anten tasarımının geri-dönüş kaybı karakteristiği 


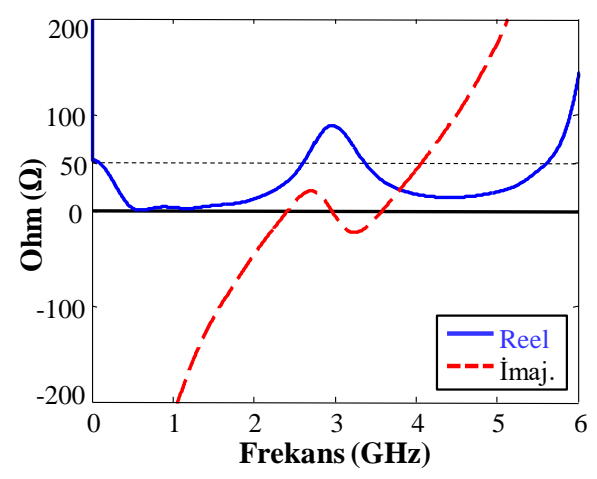

Şekil 3. Anten tasarımının giriş empedans karakteristiği

Şekil 4'te, üretimi gerçekleştirilen anten tasarımının ölçüm sonucu ile simülasyon sonucu birlikte verilmiştir. Görüldüğü üzere, sonuçlar arasında bir miktar kayma mevcut olsa da geniş bant karakteristiği elde edilebilmiştir. Aralarındaki farklılığın ise üretim hatalarından kaynaklandığı düşünülmektedir. $S_{11}$ ölçüm sonuçları Rohde \& Schwarz ZVB8 Vector Network Analizörü kullanılarak elde edilmiştir.
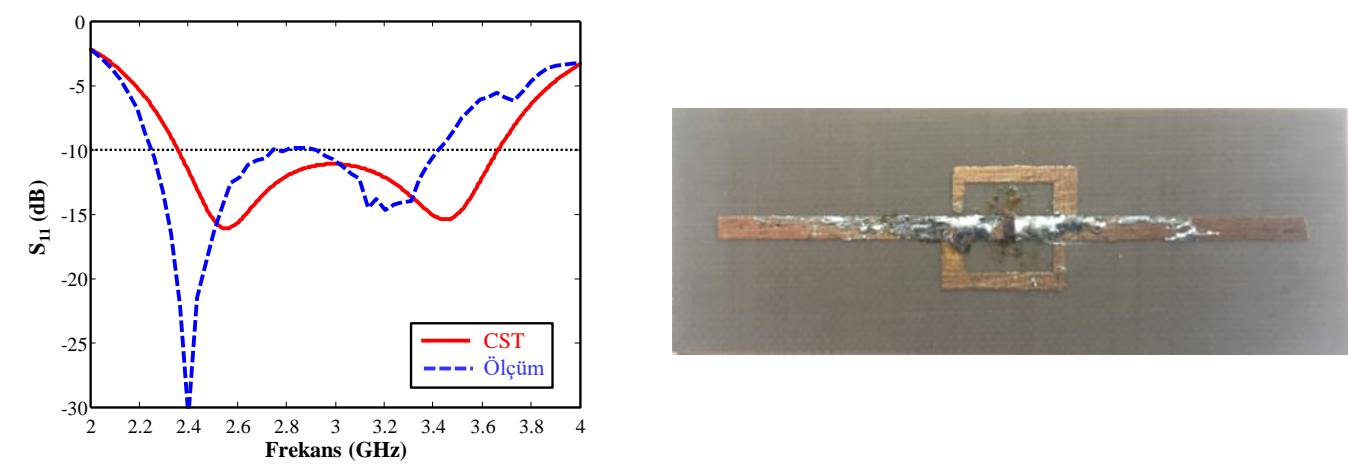

Şekil 4. Tasarımın ölçüm ve simülasyon sonuçları

Şekil 5'te, ilgili bandın merkez frekansı olan $3 \mathrm{GHz}$ 'deki tasarıma ait ışıma örüntüsü yer almaktadır. Görüldüğü üzere, eklenen parazitik elamanlar dipol yapısının ışıma karakteristiğini bozucu bir etkiye neden olmamıştır. Anten yapısı istenildiği gibi yönsüz ışıma karakteristiğine sahiptir ve ilgili frekansta simülatör tarafindan hesaplanan yönlendirme kazancı $2.36 \mathrm{dBi}$ seviyelerindedir. Ayrıca aynı frekanstaki antenin toplam verimliliği ise $-0.428 \mathrm{~dB}$ 'dir $(\sim \% 90)$.
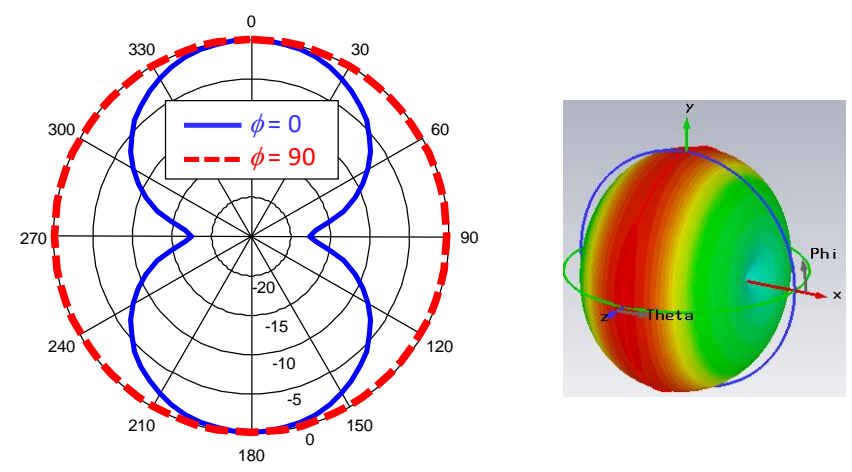

Şekil 5. Tasarımın 3.0 GHz'deki ışıma örüntüsü 


\section{PARAMETRIK ÇALIȘMALAR}

Önerilen geniş bantlı anten tasarımının performansını etkileyen parametreleri göstermek için bir dizi parametrik çalışma gerçekleştirilmiştir. Bu çalışmalar sonucunda dipol elemanının ilk bandın (soldaki) rezonans frekansını belirlemede etkili olduğu, parazitik elemanların boyutlarının ise ikinci frekans bandının (sağdaki) performansını belirlemede etkili olduğu gözlemlenmiştir. Boyutların optimize edilmesi sonucunda da istenilen geniş bantlı anten performansının elde edilebileceği anlaşılmıştır. Gerçekleştirilen parametrik çalışmalar ve değerlendirmeleri aşağıda verilmiştir.

\section{A. DIPOL ELEMANININ KARAKTERISTİĞE ETKISİ}

İlgili geniş bant karakteristiği için dipol anten elemanının uzunluğu önemli bir rol oynamaktadır. Şekil 6'da dipol uzunluğunun anten karakteristiğine olan etkisi yer almaktadır. Görüldüğü üzere dipol elemanı, istenen geniş bant performansını elde edebilmek için birleştirilen bantlardan ilkinin (soldaki) rezonans frekansını belirlemektedir. Beklendiği üzere dipol uzunluğu artırıldıkça birinci bant düşük değerlere doğru kaymakta fakat ikinci bandın seviyesinde değişme olsa da frekansında bir kayma oluşmamaktadır. Böylece istenen geniş bant özelliği bozularak yerine çift bant karakteristik elde edilmektedir.

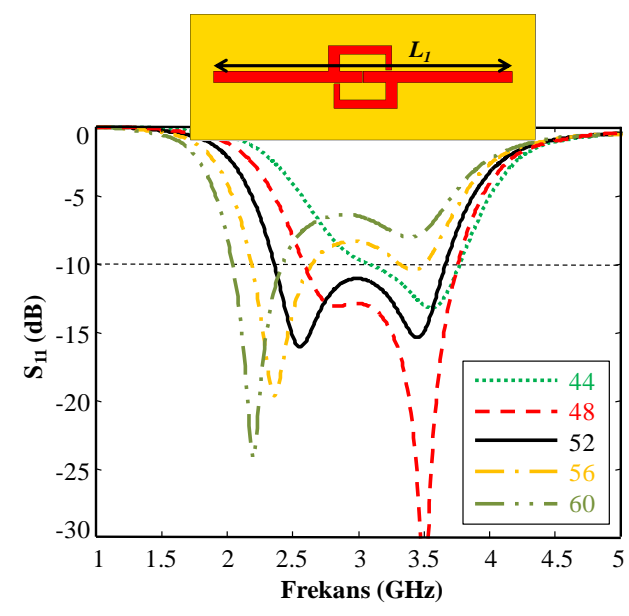

Şekil 6. Dipol elemaninin anten karakteristiğine olan etkisi

\section{B. YÜKLEME ELEMANININ KARAKTERISTTIĞE ETKISİ}

İstenen geniş bant anten karakteristiği için önemli rol oynayan diğer parça ise yükleme elemanlarıdır. Şekil 7'de, yükleme elemanlarının $L_{2}, L_{3}$ ve $L_{4}$ boyutlarının anten performansına olan etkileri yer almaktadır. Yapılan parametrik analizler sonucunda, yükleme elemanlarının birleştirilen ikinci bandın rezonans frekansını belirlediği gözlemlenmektedir. Beklenildiği üzere, yükleme elemanlarının boyutları azaldıkça ikinci bant yüksek frekanslara doğru kaymakta fakat buna karşın birinci bantta seviyeler dişında pek bir değişim oluşmamaktadır. Böylece ilgili boyutların değiştirilmesi sonucunda arzu edilen geniş bant özelliği kaybolmakta ve yerini çift bantlı anten karakteristiğine bırakmaktadır. 

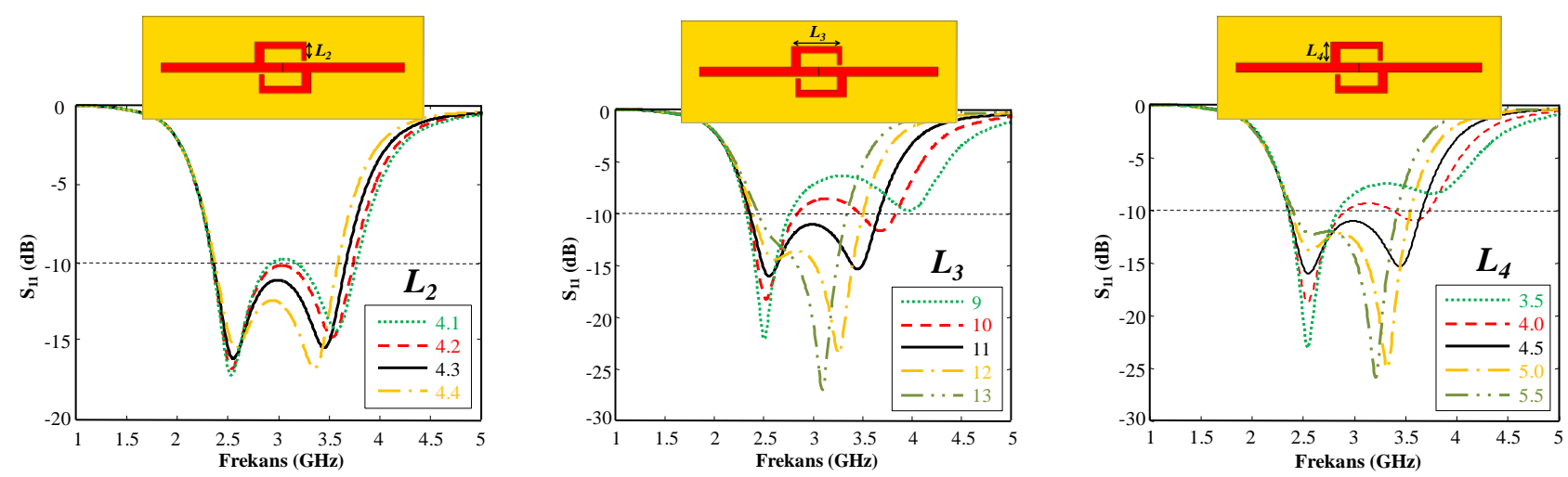

Şekil 7. $L_{2}, L_{3}, L_{4}$ boyutlarının anten karakteristiğine olan etkisi (boyutlar mm)

\section{SONUÇLAR}

Bildiride, WLAN/WiMAX bantlarını kapsayan uygulamalarda kullanılabilecek, 2.36-3.67 GHz aralığında performans gösteren bir geniş bantlı mikroşerit dipol anten tasarımı tanıtılmıştır. İlgili tasarımda, $52 \mathrm{~mm}(\sim \lambda / 2)$ uzunluğundaki mikroşerit dipol anten elemanının beslemesi yakınlarına asimetrik ve aynı düzlemde olacak şekilde iki adet bükülmüş yükleme elemanı eklenmiştir. Bu eklemeler sayesinde \%10'luk bant genişliğine sahip olan standart bir mikroşerit dipol antenin bant genişliği \%43'e çıkarılabilmiştir. Yapılan bu eklemeler sonucunda antenin 1şıma örüntüsü karakteristiğinde herhangi bir bozulma olmamıştır. Önerilen geniş bantlı anten, yönsüz 1şıma örüntüsüne ve $2.36 \mathrm{dBi}$ seviyelerindeki yönlendirme kazancına sahiptir. Tasarımın ilgili frekanstaki hesaplanan toplam 1şıma verimliliği ise $-0.428 \mathrm{~dB}$ 'dir. Ayrıca bildiride, tanıtılan anten tasarımının CST Microwave Studio programı ile elde edilmiş farklı parametrik çalışma sonuçlarına da yer verilmiştir. Bu çalışmalar sayesinde ilgili geniş bantlı karakteristiğin iki farklı bandın birleştirilmesi ile elde edildiği gözlemlenmiştir.

TEȘEKKÜR: Değerli katkılarından dolayı Dr. Öğr. Üyesi Mustafa H.B. Uçar'a ve Prof. Dr. Yunus E. Erdemli’ye sonsuz teşekkürlerimi sunarım.

\section{KAYNAKLAR}

[1] A. Sondaş, "Metamateryal altyapılı ve halka yüklemeli mikroşerit anten tasarımları ve gerçeklenmesi,” Doktora tezi, Elektronik ve Bilgisayar Eğitimi ABD, Kocaeli Üniversitesi, Kocaeli, Türkiye, 2011.

G. Kumar ve K.P. Ray, Broadband Microstrip Antennas, USA: Artech House, 2003.

[3] K.L. Wong, Compact and Broadband Microstrip Atennas, USA: John Wiley \& Sons Inc., 2002.

[4] Commission's Rules Regarding Ultra-Wideband Transmission System, FCC, FCC 02-48, 2002. 
[5] X. Qing ve N. Yang, "A folded dipole antenna for RFID," IEEE AP-S International Symposium, Monterey, USA, 2004, pp. 97-100.

[6] S.L. Chen ve K.H. Lin, "A Folded Dipole with Closed Loop for RFID Applications," Progress In Electromagnetics Research Symposium, Honolulu, USA, 2007, pp. 2281-2284.

[7] N. Keskin, T. İmeci, S.M.T. Rahman ve E. Karaçuha, "UHF RFID Pasif Etiket için Dipol Anten Tasarımları," IEEE 22nd Signal Processing and Communications Applications Conference (SIU), Trabzon, Türkiye, 2014, ss. 1134-1137.

[8] M. Ali, S.S. Stuchly ve K. Caputa, "A wide-band dual meander- sleeve antenna," Journal of Electromagnetic Waves and Applications, vol. 10, no. 9, pp. 1223-1236, 1996.

[9] K.V.S. Rao, P.V. Nikitin ve S.F. Lam, "Antenna design for UHF RFID tags: a review and a practical application," IEEE Trans. Antennas Propagation, vol. 53, no. 12, pp. 3870-3876, 2005. 